\title{
Multiyear analysis of the dependency of the planting date on rainfall and soil moisture in paddy fields in Cambodia, 2003-2019
}

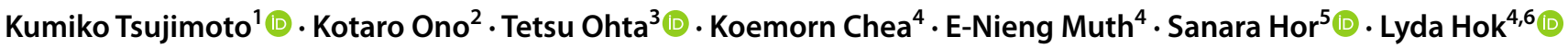

Received: 28 April 2020 / Revised: 10 June 2021 / Accepted: 17 June 2021 / Published online: 6 July 2021

(C) The Author(s) 2021

\begin{abstract}
The dependencies of the planting date on rainfall and soil moisture in paddy fields in Cambodia were analyzed to quantify farmers' empirical knowledge regarding their decision of the planting date. Remote sensing data from multiple satellites covering the 2003-2019 period were analyzed. The planting dates in rain-fed paddies ranged from April to August, with large spatial variations and year-to-year fluctuations. In years when planting was suppressed in April and May, planting was extensively enhanced in June and August compared to normal years, and vice versa. Over the northeastern side of Tonle Sap Lake and south of Phnom Penh city, the areas planted in April and May were found to have positive correlations with rainfall and soil moisture, suggesting that wetter-than-average conditions encouraged farmers to plant earlier in the season. In contrast, this relationship was unclear on the western side of Tonle Sap Lake, where the rainfall amounts were larger throughout the year than in other areas in Cambodia. In this region, the relationship between the planting area and soil water availability was either unclear or was even slightly negative from June to August. Since more frequent dry spells have been detected after the onset of the rainy season in recent years, further studies and disseminations of potential changes in dry spells are important for the agronomic adaptation of planting dates under climate change.
\end{abstract}

Keywords Planting date $\cdot$ MODIS $\cdot$ AMSR $\cdot$ GSMaP $\cdot$ Empirical knowledge $\cdot$ Agronomic adaptation

\section{Introduction}

Cambodia is part of mainland Southeast Asia and is located in the southern portion of the Indochina Peninsula. It is bordered by Laos, Thailand, and Vietnam and has a coastal area

Kumiko Tsujimoto

tsujimoto@okayama-u.ac.jp

1 Graduate School of Environmental and Life Science, Okayama University, 3-1-1 Tsushima-naka, Kita-ku, Okayama 700-8530, Japan

2 Faculty of Environmental Science and Technology, Okayama University, Okayama, Japan

3 Assistance Unit for Research and Engineering Development (U-PRIMO), Okayama, Japan

4 Faculty of Agronomy, Royal University of Agriculture, Phnom Penh, Cambodia

5 Faculty of Land Management and Land Administration, Royal University of Agriculture, Phnom Penh, Cambodia

6 Center of Excellence on Sustainable Agricultural Intensification and Nutrition, Royal University of Agriculture, Phnom Penh, Cambodia facing the Gulf of Thailand (Fig. 1a). Of its population of 16 million, 77\% lived in rural areas as of 2018 (FAO 2019). Agricultural land occupied approximately $55,660 \mathrm{~km}^{2}$ in Cambodia and accounted for $31 \%$ of the entire area in 2018 (FAO 2019). The paddy area in 2017 was reported to be $29,510 \mathrm{~km}^{2}$ (JICA 2019), occupying $53 \%$ of the agricultural land. Under the tropical monsoon climate, rice can be cultivated year-round, but approximately $81 \%$ of rice production results from wet-season cultivation (Wang et al. 2017).

Although the contribution of industry has risen greatly in recent years (World Bank Group 2020), a substantial proportion of the Cambodian population is still dependent on farming and fisheries, and agriculture contributes $33 \%$ to the national gross domestic product (GDP), playing a key role in Cambodian economic development. In 2010, the Cambodian government published a "Policy document on promotion of paddy rice production and export of milled rice," which stated the ambition to turn Cambodia into a key rice-exporting country in the international market (Kea et al. 2019). Given the high dependency of the households and national economy on agriculture, ensuring higher and more stable rice production is a key challenge for national 


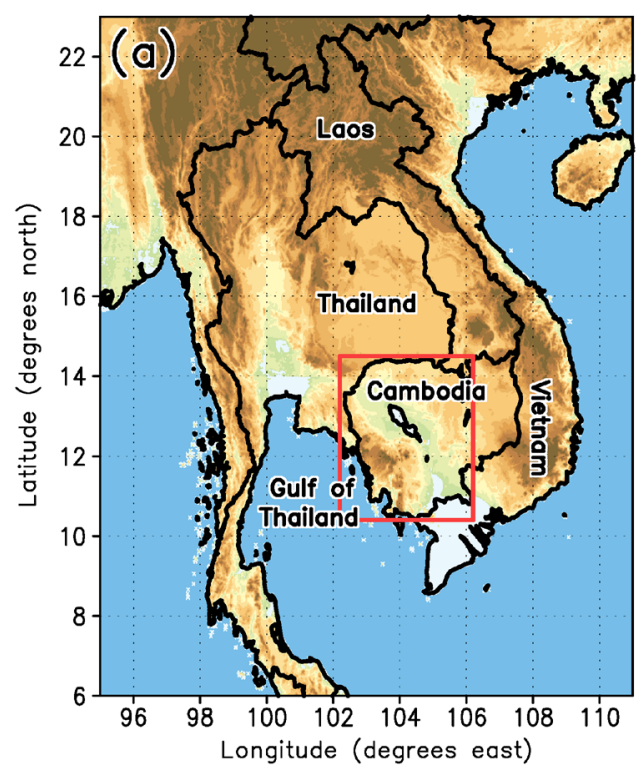

Fig. 1 Location of the study area. a Elevation map of the Indochina Peninsula with the study area indicated by a red rectangle. b Enlarged view of the study area shown with five subareas (1-5) and major

development. On the other hand, irrigated agricultural land represents approximately $20 \%$ of the total cultivated area (Ministry of Water Resources and Meteorology (MOWRAM 2012), and most of this agricultural land is rain-fed. Thus, agriculture in Cambodia is sensitive to climatic variables. Over the past 20 years, the rice yield in Cambodia has doubled from 1.8 (1998) to $3.6 \mathrm{t} / \mathrm{ha}$ (2018), but a fluctuation in the rice yield has been detected underneath this increasing trend (FAO 2019).

Although climatic variables are not easily controllable in each farm field, factors such as cultivars, soil, water, and nutrients can be managed to counteract the adverse effects of climate change. The effectiveness of such agronomic adaptations or mitigation strategies has been examined, for example, in eastern India (Krishnan et al. 2007), Vietnam (Shrestha et al. 2016), northeast Thailand (Babel et al. 2011), Tamil Nadu (Bhuvaneswari et al. 2014), and Burkina Faso (Waongo et al. 2015). Examples of such agronomic adaptations include changing the cultivar, planting date, sowing density, irrigation management, and fertilizer application. Among these changes, the effectiveness of adapting to climate change by shifting the planting date has been widely suggested in earlier studies to prevent high-temperature damages resulting from climate change, to suppress crop water requirements, or to prevent drought stress on rain-fed rice (e.g., in northern Iran by Darzi-Naftchali and Karandish (2019), in Bangladesh by Rahman et al. (2017), in India

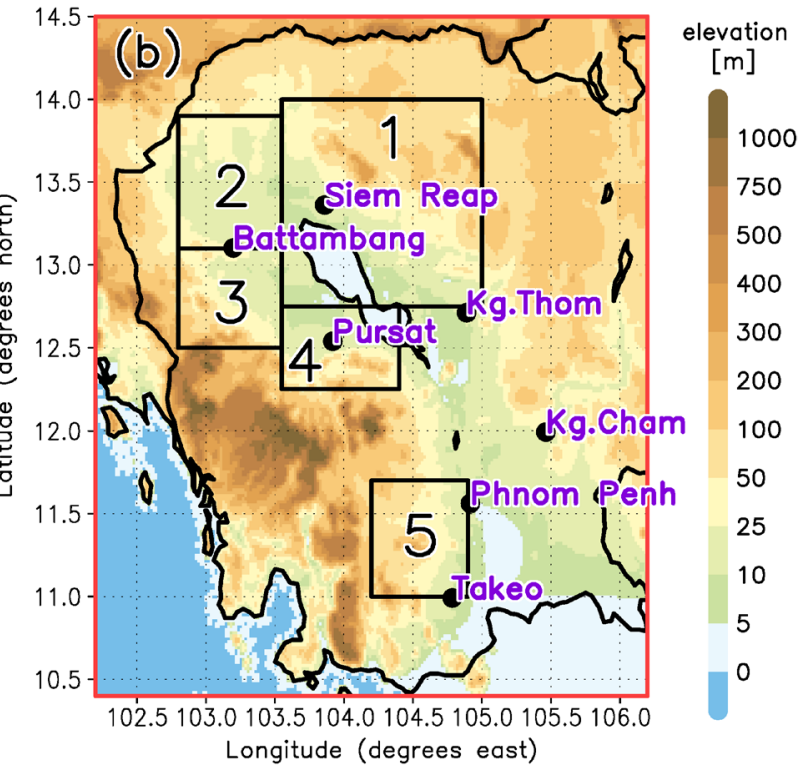

city names. The closed curve in the center of the study area is Tonle Sap Lake. The elevation data are from the global elevation data set GTOPO30 (USGS 1996)

by Li et al. (2015), and in South Korea by Yoon and Choi (2019)).

Several studies on Cambodia have also been conducted. So Im et al. (2014) used multimodel outputs from global atmospheric models with a combined hydrological and crop model to derive the optimum planting date in terms of minimizing the drought effect on rain-fed paddy rice production. Their results indicated that the optimum time for planting under future climate conditions was likely to be in September, approximately, 1 month later than the optimum time in the present climate. Li et al. (2017) conducted a similar study across the Indochina Peninsula considering the $\mathrm{CO}_{2}$ fertilization effect and reported that shifting the planting date 20 days later relative to the baseline planting date would mitigate the negative impact of climate change on rice production in Cambodia. Wang et al. (2017) examined the impact of climate change on rice production in Cambodia for two rice cultivars through field experiments, as well as numerical model simulations. They analyzed the effectiveness of adaptation strategies by changing the planting date and varying the fertilizer application rate. Their results demonstrated decreasing yields with earlier planting dates and increasing yields with later planting dates. Although these three previous studies of Cambodia used different approaches and different crop models, all of them suggested later planting to mitigate the adverse effects of climate change. Similarly, a study conducted in northeast Thailand (Babel et al. 2011) also reported that delaying sowing for 20-30 days could 
increase rice yields in the future climate, although it was also suggested that any further delay may reduce rice yields due to reduced water availability.

Such studies examined the effectiveness of potentially adjusting the planting date to adapt to future climate change. In the current study, we observed that in rain-fed paddy fields in Cambodia, local farmers have always adjusted their agricultural management according to annual variations in rainfall and soil water availability. The planting date is not fixed to a certain calendar date, and it is often the case that the growing stages of rice plants are quite different among adjacent fields. Our interviews with farmers revealed that they adapt their agronomic management practices (e.g., cultivation area; season; rice cultivar; and planting method, that is, direct seeding or transplanting) based on water availability, as well as on the market situation and labor limitations. Since the major limitation to rice planting in this region is water rather than radiation or temperature (Tsujimoto et al. 2008), it seems that farmers plant rice wherever the soil water is sufficient for its cultivation. This observation allowed us to hypothesize that to some extent, farmers have already adapted to climate (rainfall) variability when determining the planting date. In our study, we tried to quantify the farmers' perceptions that determined the planting date according to rainfall and soil water availability.

Numerous studies have been reported on the dependence of the planting date on rainfall in Africa, where the drought effect is more severe than it is in Cambodia. Wolf et al. (2015) pointed out that crop production is highly variable and uncertain for rain-fed agriculture in Africa, so ensuring the optimal timing of farm operations is very important. Farmers should adapt sowing dates based on their own experience to avoid dry spells at the beginning of the rainy season and to avoid drought periods at the end of crop growth. From a multiyear field survey conducted in southwestern Niger, Marteau et al. (2011) found that most farmers started to sow just after the first rain event of at least $10 \mathrm{~mm}$ but not necessarily more than $20 \mathrm{~mm}$ and that there was a strong correlation between the spatial averages of the rainfall onset and the sowing date. However, since the monsoon season had not yet begun at the time of sowing, the probability of a postsowing dry spell was high, and dry spells in which the rainfall amounts were less than $10 \mathrm{~mm}$ lasting at least 7 days after an initial wet spell resulted in sowing failures.

Compared to Africa, Cambodia has a more humid and water-rich environment, as it is under a tropical monsoon climate. However, Cambodia has distinct dry and wet seasons, and the timing of the onset and withdrawal of the Asian summer monsoon show high interannual variabilities, leading to high interannual variabilities in the seasonal rainfall amounts (Tsujimoto et al. 2018). In addition, a dry spell is often observed just after the onset of the rainy season, posing a high risk for wet-season agriculture. Sawano et al. (2008) analyzed the relationship between the planting date and rainfall amount over rain-fed lowland rice paddies in northeast Thailand, an adjacent region to Cambodia. Field surveys conducted in 2004 and 2005 revealed that the transplanting date could be expressed well as a function of the cumulative rainfall amount from June onward. However, limited studies have been conducted on the existing relationship between the planting date and rainfall amount (or weather conditions, soil water availability, etc.) in Cambodia and the surrounding regions. Farmers managing rain-fed paddy fields in Cambodia would have adapted to-and will, in the future, adapt to-climatic variations by adjusting the planting date to some extent according to the yearly fluctuations in the Asian summer monsoon. However, most previous studies that assessed the impacts of climate change on rice production with climate models and crop models assumed a fixed growing season instead of accounting for annual climate variabilities. Quantifying farmers' empirical knowledge to determine the optimum planting date can contribute to crop production simulations under the future climate and, in turn, clarify the factors that must be changed when determining the planting date.

In this study, we examined the existing dependency of the planting date on the soil moisture and rainfall amount in paddy fields in Cambodia, where rain-fed paddies dominate, using remotely sensed data. Although farmers' perceptions, experimental knowledge, and agronomic management may differ among individuals, villages, and regions, we tried to retrieve the regional-scale tendency as a whole using globally accessible climatic and land surface data sets.

\section{Materials and methods}

\section{Study area}

The study area in Cambodia $\left(10.4-14.5^{\circ} \mathrm{N}, 102.2-106.2^{\circ}\right.$ E) is indicated by the red rectangle in Fig. 1a. We selected five subareas (Fig. 1b) around Tonle Sap Lake in this study: the northeastern side of the lake (subarea 1), the area north of Battambang (subarea 2), the area south of Battambang (subarea 3), Pursat (subarea 4), and the area south of Phnom Penh (subarea 5). Paddy cultivation dominates these areas, and field surveys (Hirooka et al. (2016) and our unpublished works) have been carried out in these regions on agricultural management and rice crop growth.

According to a report by the Cambodian Agricultural Research and Development Institute (CARDI 2013, 2014), the rice cultivation seasons last from approximately January to May for early wet-season rice, from June to 
December for wet-season rice, and from January to April for dry-season rice.

\section{Estimation of the planting date}

The estimation of the planting date was based on the algorithm created by Tsujimoto et al. (2019). A detailed explanation of the algorithm and its validation results in Pursat are shown in Tsujimoto et al. (2019), and only the parts of the algorithm that are essential to this study are explained in this section. The data we used to detect the planting date were obtained from the enhanced vegetation index (EVI) product published by the United States Geological Survey (USGS), which was created from the observations of the Moderate Resolution Imaging Spectroradiometer (MODIS) onboard the Terra and Aqua satellites. We obtained the MODIS/ Aqua Vegetation Indices 16-Day L3 Global 250-m SIN Grid V006 (MYD13Q1, available from July 4, 2002 to the present (USGS 2020a)) and MODIS/Terra Vegetation Indices 16-Day L3 Global 250-m SIN Grid V006 (MOD13Q1, available from February 18, 2000 to the present (USGS 2020b)) products and used them for the analysis. With these two data sets, we first generated 8-day composite data with a 500-m spatial resolution over the entirety of Cambodia for the 17 years from 2003 to 2019. Then, referring to the Global Land Cover Characterization (GLCC) ver1.2 data (Loveland et al. 2000; USGS 2018), we extracted only the cropland grids for further analysis. The planting date was then estimated using the algorithm of Tsujimoto et al. (2019) by applying the above data set for each $500-\mathrm{m} \times 500-\mathrm{m}$ grid for each year from 2003 to 2019 . The time window used to search for the estimated planting date from the heading date was set to 56-112 days, and the planting date was defined as the day with the largest positive EVI slope within the time window. Although the day with the minimum EVI value was estimated as the planting date in the original algorithm by Tsujimoto et al. (2019), by applying this algorithm to a larger area, we found erroneous detections in which the minimum EVI value was not followed by an increase in EVI in the following days. In this study, we thus defined the planting date by analyzing the EVI time series.

It should be noted that this algorithm has been developed and validated under transplanted paddy field conditions, and the planting days in direct-seeding paddies are approximately 2 months earlier in Cambodia than the planting dates estimated by this algorithm (Tsujimoto et al. 2019). In this study, all the analyses were conducted under the assumption that the paddies were transplanted; thus, it should be noted that farmers' actual decisions about sowing and planting in direct-seeding paddies were made earlier than the results shown in this paper.

The algorithm created by Tsujimoto et al. (2019) also estimates the number of croppings in a year. In Cambodia, most rice cultivation occurs in the rainy season, and dryseason rice cultivation, or the second cultivation, is mostly limited to areas where irrigation facilities are available. To carry out an analysis on the relationship between the planting date and water availability while focusing only on rainfed paddy fields, we first estimated the number of croppings in each year and then performed further analyses only on the cropland grids in which the number of croppings in each year was one.

\section{Rainfall data}

Because data with a high spatiotemporal resolution were available for the entire study period, we used the Global Satellite Mapping of Precipitation (GSMaP) data published by the Japan Aerospace Exploration Agency (JAXA). This satellite-based hourly precipitation product covers the whole globe with a 0.1-degree gridded resolution (Kubota et al. 2007, 2009). Of the various GSMaP products (JAXA 2019), the reanalysis product (GRMaP_RNL (v6), available from March 2000 to February 2014) and the gauge-calibrated standard product (GSMaP_Gauge (v7), available from March 2014 to the present) were used for the analyses in this study. The original GSMaP data sets were first interpolated to a $500-\mathrm{m} \times 500-\mathrm{m}$ spatial resolution, as were the MODISEVI data sets, to be used for the following analysis.

When using the GSMaP product, we compared the rainfall amounts indicated therein with rain-gauge observations from gauges we installed and maintained for data collection in 2010-2015 (Tsujimoto et al. 2018). Although the available period of the gauges was limited compared to that of GSMaP, the combined use of GSMaP and the gaugeobserved data enabled a reliable discussion of the rainfall characteristics from 2000 to the present.

\section{Soil moisture data}

The soil water content represents the historical record of rainfall, reflects hydrological processes such as infiltration, surface runoff, evapotranspiration, and soil water flow and, more directly, affects agricultural management. However, in general, observed data on the spatiotemporal distribution of soil moisture are much scarcer than observed rainfall data; thus, it is difficult to analyze multiyear relationships between soil moisture and agricultural management. In this study, we analyzed remotely sensed soil moisture data in addition to the rainfall data in the GSMaP product to assess the local water availability for rain-fed paddy fields and examined the relationship of soil moisture with the planting date.

The data used herein were the satellite microwave remote sensing product published by JAXA (JAXA 2020a, b). This product provides global surface soil moisture data from 2012 to the present based on observations from the Advanced 
Microwave Scanning Radiometer 2 (AMSR2) onboard the Global Change Observation Mission-Water (GCOM-W) satellite. A similar data set is available for the earlier periods in 2002-2011 based on observations by the Advanced Microwave Scanning Radiometer from the Earth Observing System (AMSR-E) onboard the Aqua satellite. In this study, we used the AMSR-E and AMSR2 data to analyze the soil moisture tendency from 2003 to 2019. More specifically, the level-3 products with $10-\mathrm{km}$ resolutions (L3. SMC_10) from AMSR-E (the product with the AMSR2 format) and AMSR 2 were used.

Although the AMSR2 soil moisture product is provided at a $10-\mathrm{km}$ gridded spatial resolution, the soil moisture retrieval algorithm uses observations obtained at 10 and $36 \mathrm{GHz}$, and the corresponding footprints are $24 \times 42 \mathrm{~km}$ and $7 \times 12 \mathrm{~km}$ ellipses (JAXA 2016; Kaihotsu et al. 2019). Since we focused on regional-scale, annual variability rather than on location-to-location soil water variability, we obtained area-averaged values over the target area and used these values to detect the seasonal evolution in soil moisture and its annual fluctuations as regional averages. The original AMSR2 and AMSR-E data sets were first interpolated to a $500-\mathrm{m} \times 500-\mathrm{m}$ spatial resolution, as were the MODIS-EVI data sets, and only the cropland grids were extracted to calculate the area-averaged values.

\section{Results}

\section{Planting date}

Figure 2 shows the estimated number of croppings in 2019 as an example. Most of the cropland around Tonle Sap Lake was categorized as one-time cropping land, whereas second or third croppings were detected near the Mekong Delta in Vietnam. Although further validation is required for a detailed study, the characteristics shown in Fig. 2 are reasonable compared to the existing reports and studies conducted in Cambodia and the Mekong Delta (e.g., Nguyen et al. 2015; JICA 2019), and we used the estimated number of croppings in each year to mask out the multicropping area in our analysis.

Figure 3 shows the spatial distribution of the estimated planting date at a 500-m $\times 500-\mathrm{m}$ grid resolution; the plot shows only the single-cropping area in each year. Reddish colors show earlier plantings, and bluish colors show later plantings. The differences in the distribution of the colored grids correspond to the differences in the distribution of the single-cropping areas, which are regarded as rain-fed paddies in this study. The estimated planting date for each subarea is summarized in Fig. 4 with a boxplot, indicating the minimum, lower quartile, median, upper quartile, and maximum values of the estimated planting date for each year in each subarea, obtained using all the planted grids
Fig. 2 Estimated number of croppings in 2019 over the study area (green for one-time cropping, blue for double croppings, and magenta for triple croppings). Only the cropland grids are shown in color. (Color figure online)

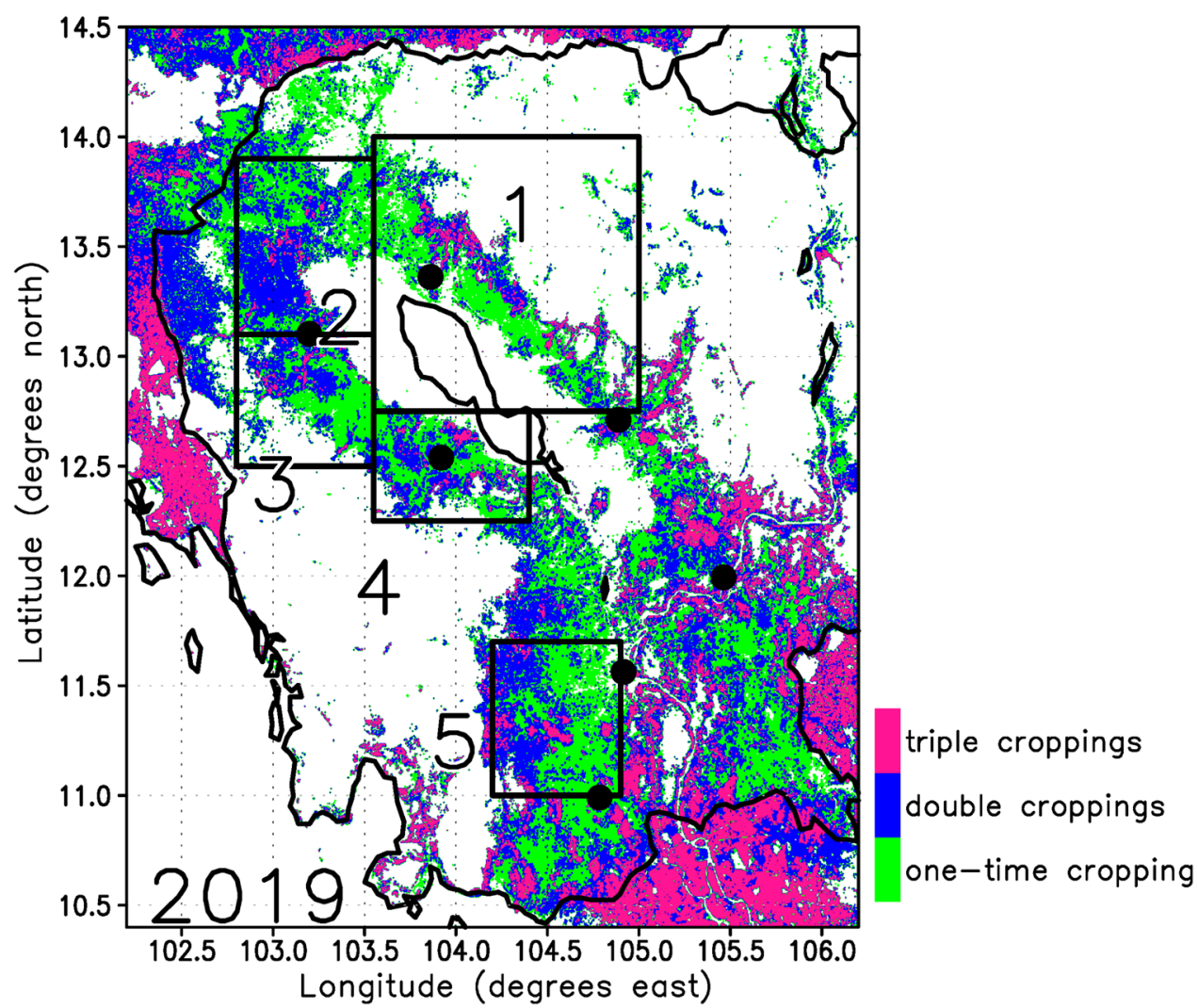




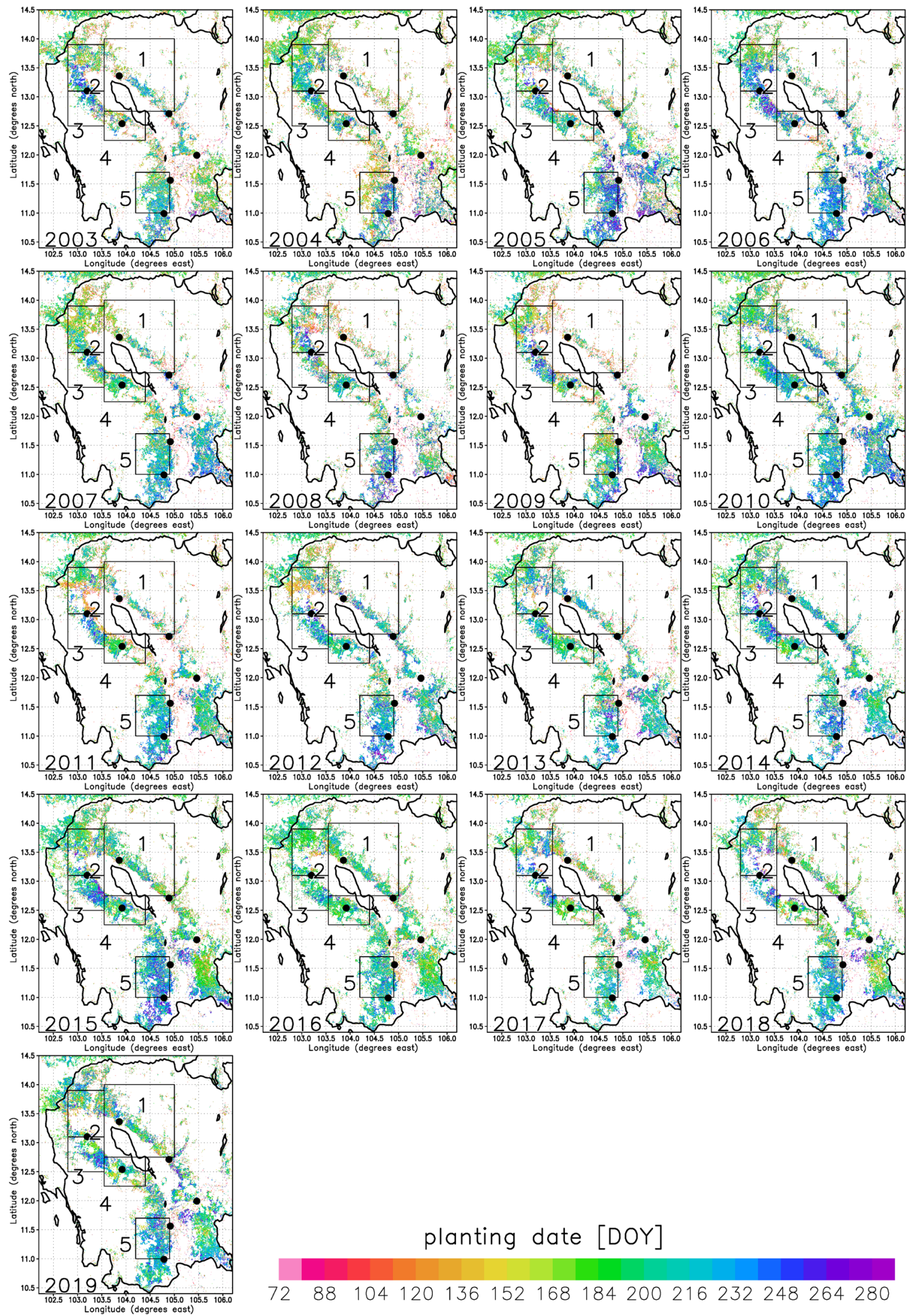

Fig. 3 Estimated planting date (shown as the day of year (DOY)) for each year in 2003-2019 for the areas with one-time croppings in each year 
in each year in each subarea. The red horizontal line on each boxplot indicates the multiyear (2003-2019) mean of the estimated planting date in each subarea. The monthly accumulated number of planted grids is also indicated in Fig. 4 by the bar.

The monthly bars in Fig. 4 show that the planting dates in rain-fed paddies range widely from April to September, and the planting date most frequently occurred from June to August, during the full-monsoon season. As obtained from the multiyear mean of the area-averaged values (indicated by the red line in the boxplot in Fig. 4), planting occurred on the days of the year (DOYs) 177, 183, 200, 183, and 196 in subareas 1-5, corresponding to June 26, July 2, July 19, July 2 , and July 15 , respectively. The multiyear-mean planting date was found to be earliest in subarea 1 , followed by subareas 2 and 4; this value occurred latest in subarea 3 . The spatial and annual variabilities in the planting date were quite large in all the subareas throughout the years from 2003 to 2019 (Fig. 3 and boxplots in Fig. 4). When the areal differences were compared among the subareas, subarea 3 was characterized by later planting and a smaller spatial variability than those of the other subareas.
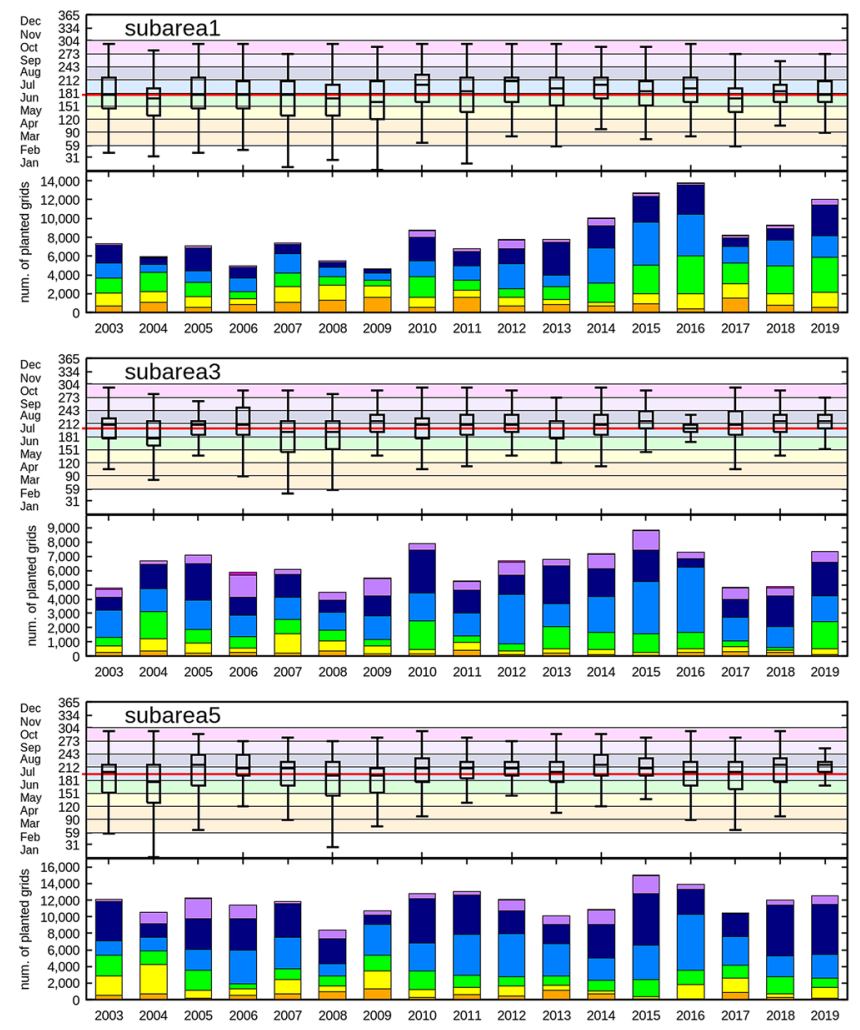

Fig. 4 Boxplot (upper panel) and monthly accumulation (lower panel) of the estimated planting date (shown as the day of year (DOY)) for each year in 2003-2019 for each subarea. The red horizontal line in the boxplot shows the 2003-2019 mean for each sub-

\section{Dependency of the planting date on rainfall}

The monthly rainfall amounts obtained from the GSMaP reanalysis (from 2003 to February 2014) and the GSMaP standard (after March 2014) are shown in Fig. 5 as areal averages over each subarea. Compared with the rain-gauge observations in 2010-2015 (Tsujimoto et al. 2018), the amount of annual rainfall was greater in the GSMaP data sets, but the annual variation was similar, with smaller amounts of rainfall occurring in 2014-2015 compared to 2011-2013. To carry out a long-term analysis, we used GSMaP data in this study. Overall, the rainfall amount was larger on the western side of Tonle Sap Lake (subareas 3 and 4) and smaller on the northeastern side (subarea 1) and the southern side (subarea 5) of the lake.

In a similar study that examined the relationship between the planting date in rain-fed paddy fields and rainfall in northeast Thailand, Sawano et al. (2008) found that the planting date can be expressed well as a function of the cumulative rainfall from June onward. To compare the results obtained herein with their results, the accumulated rainfall amount from June 1 onward and the percentage of the planted area from June 1 onward to the total planted
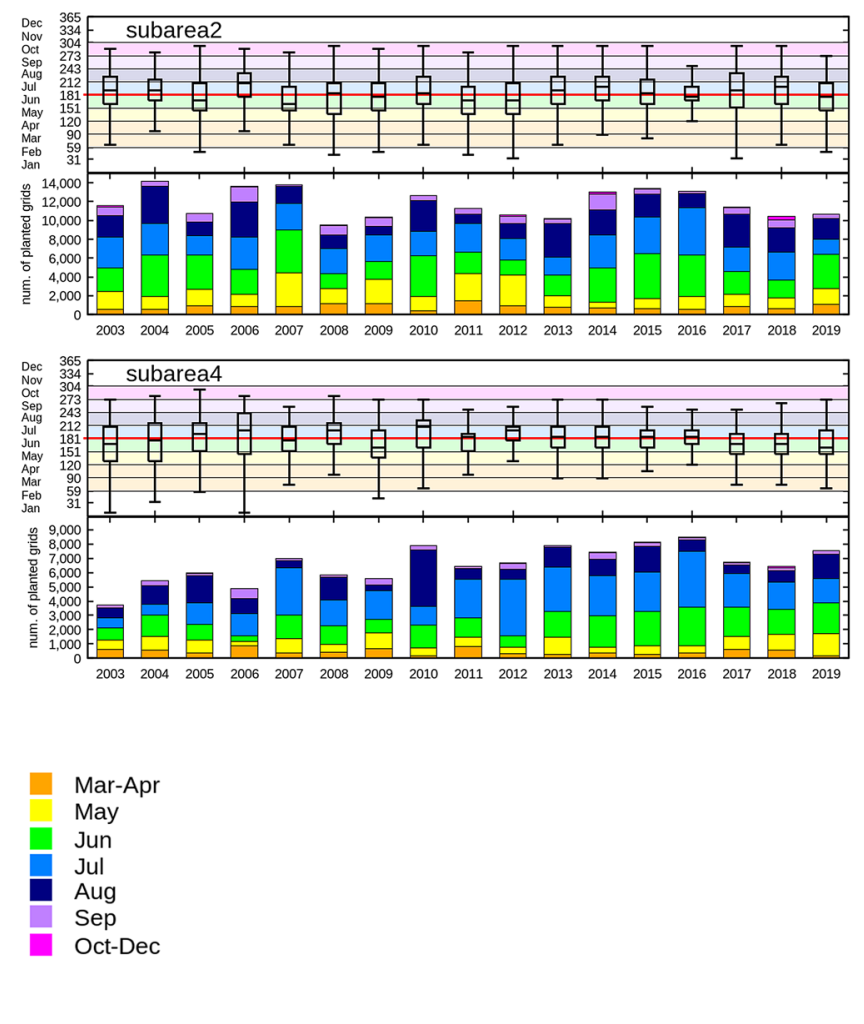

area. The boxplot indicates the minimum, lower quartile, median, upper quartile, and maximum values using data from all the planted grids, indicated as the total number of grids in the bar in each year for each subarea 


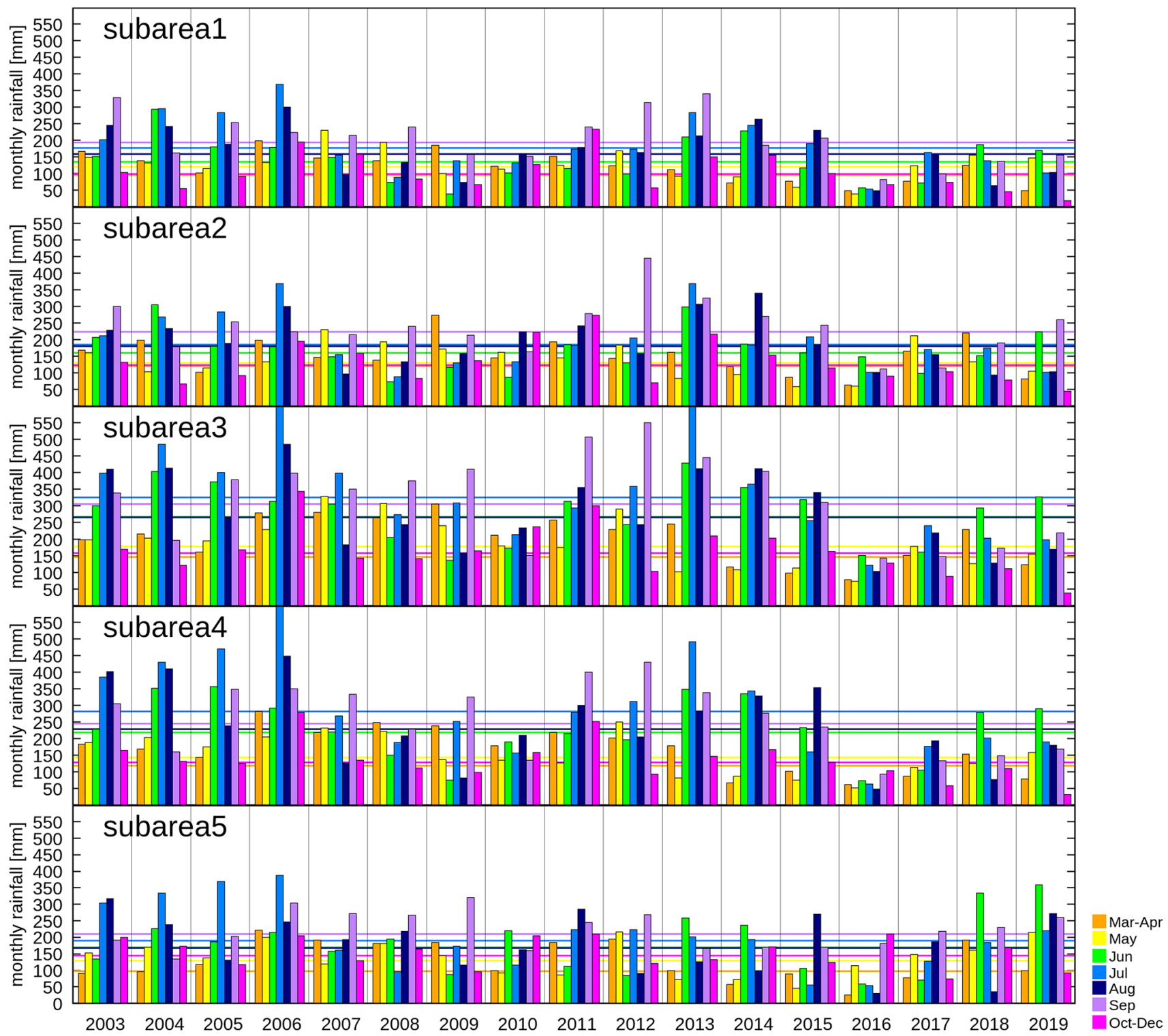

Fig. 5 Monthly rainfall in each year (bar) indicated as the 2003-2019 mean (line), shown as area-averaged values for each subarea. Monthly rainfall amounts greater than $590 \mathrm{~mm}$ are not shown in the graph

area are plotted in Fig. 6a for each year, with the regression line shown from Sawano et al. (2008). In subareas 3, 4, and 5, the 2003-2019-averaged relationships matched well with the results of Sawano et al. (2008) but with significant annual variations. In subareas 1 and 2 , the estimated results showed earlier planting with a consistent accumulated rainfall amount compared with the results reported in Sawano et al. (2008).

To study how wetter-than-average or drier-than-average conditions affected the enhancement or suppression of planting, we examined the relationship between monthly accumulated rainfall amount anomalies and the anomalies of the accumulated number of planted grids beginning in March, compared to their 2003-2019 means, for each month from
June to August (Fig. 6b) and April and May (Fig. 6c) in each subarea. The linear regression line and its Pearson productmoment correlation coefficient are also shown for each plot. For June, July, and August, which were the periods discussed in the previous paragraph, the correlations between the two anomaly types were not obvious (Fig. 6b) and were even negative to a minor extent for July in all five subareas. On the other hand, for April and May (Fig. 6c), their correlations were positive and were more significant than those obtained for June-August.

These figures suggest that the greater amount of rainfall that occurred in the premonsoon season in April-May enhanced the planting areas in 2003-2019 to some extent, while the annual fluctuation in rainfall in the full-monsoon 

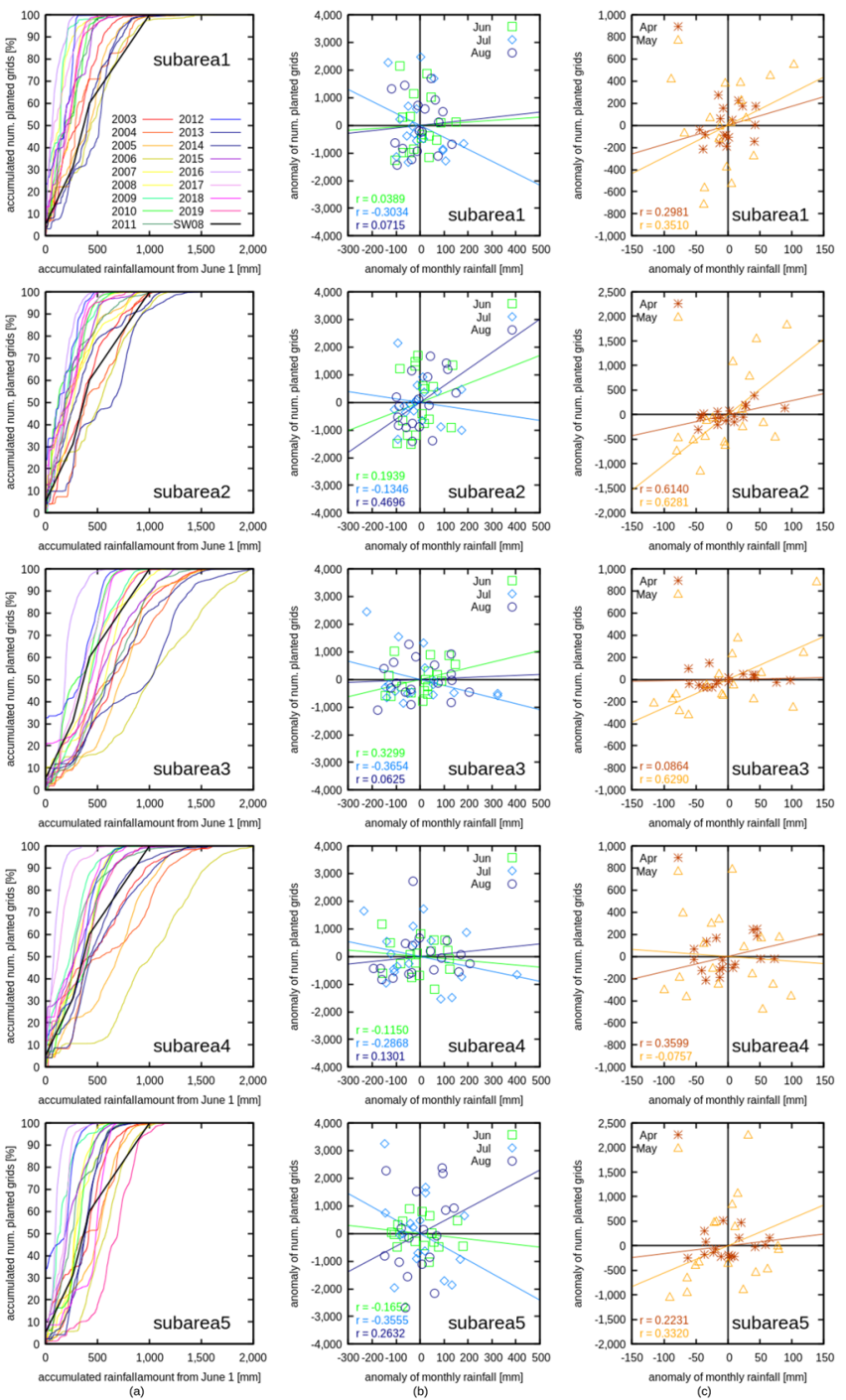

Fig. 6 a Relationship between the accumulated rainfall amount from June 1 and the percentage of the planted area from June 1 to the total planted area compared with the regression line shown in Sawano et al. (2008) (indicated as SW08 in the legend). b, c Relationship between the anomalies of the monthly rainfall amount and the accumulated number of planted grids. $\mathbf{d}$, e Relationship between

season from June to August affected the farmers' planting to a lesser extent.

\section{Dependency of the planting date on soil moisture}

Similar to the discussion in the previous subsection, the relationship between the monthly averaged soil moisture anomalies and the anomalies of the accumulated number of planted grids beginning in March is shown in Fig. 6d-e. The overall tendency of this relationship is similar to that shown for the rainfall amount in Fig. 6b-c, with positive correlations in April and May and weaker correlations
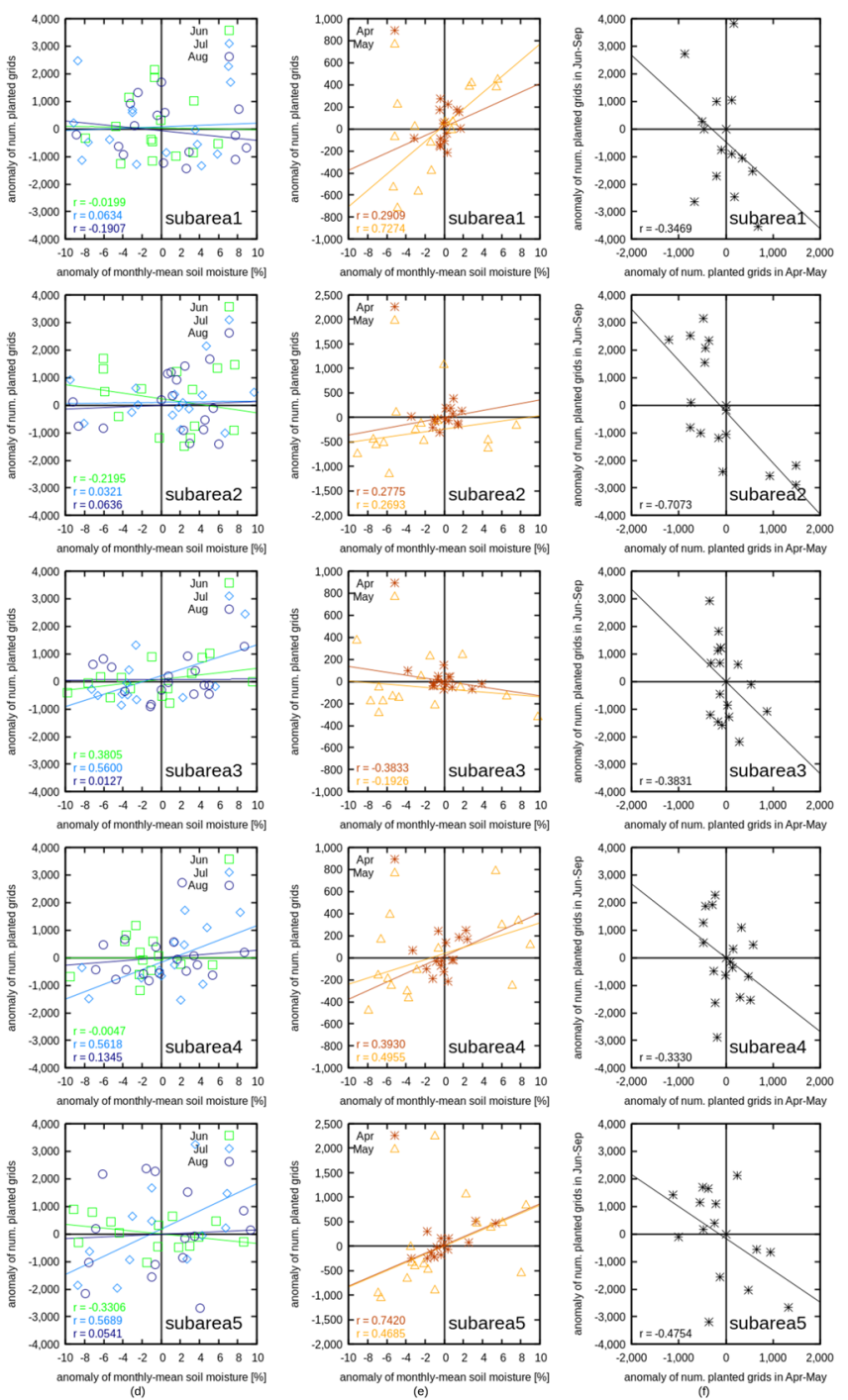

the anomalies of the monthly averaged soil moisture and the accumulated number of planted grids. The linear regression line and its Pearson product-moment correlation coefficient are shown in $\mathbf{b}-\mathbf{e}$. $\mathbf{f}$ Relationship between the anomalies of the number of planted grids in the premonsoon season (April-May) and in the full-monsoon season (June-September)

from June to August. The correlations were positive in July for the soil moisture while they were negative for the rainfall amount. Instead, the correlations in June are shown to be slightly negative for the soil moisture.

\section{The correlations of the planting date with rainfall and soil moisture}

The direction and significance of the correlations of the planting date with rainfall and soil moisture (Fig. 6b-e) are summarized in Table 1 . Although the tendencies slightly differed between rainfall and soil moisture, both relationships 
suggested that wetter conditions in April-May resulted in larger planting areas, except in subarea 3 . On the other hand, wetter conditions in June-August did not clearly correspond to increased planting areas in these months. The relationship of the rainfall amount and soil moisture with the planting area in July significantly differed, with large rainfall amounts suppressing planting and relatively wet soil enhancing planting.

Finally, Fig. $6 \mathrm{f}$ shows the relationship between the anomalies of the number of planted grids in the premonsoon season (April-May) and that in the full-monsoon season (June-September). The anomalies of the number of planted grids in June-September correlate negatively with the anomalies of the number of planted grids in the preceding season in April-May. This suggests that planting in the full-monsoon season was not greatly enhanced by the greater soil water availability in these months but was rather enhanced by the delay in the progress of planting in the preceding periods.

\section{Discussion}

\section{Potential motivation for earlier planting in April and May}

As shown in the previous section, the estimated results showed that farmers tended to plant earlier in subareas 1,2, 4 , and 5 in years with wetter conditions in the premonsoon season (April and May). This tendency was suggested in both the GSMaP rainfall data and the AMSR-E/AMSR2 soil moisture data. Subarea 3 was characterized by an unclear relationship between the wetness and the planting area in April-May, and planting in this subarea generally occurred later than in other subareas. From an analysis of the areal differences in rainfall amount shown in Fig. 5, the rainfall amount was largest in subarea 3 throughout the premonsoon, full-monsoon, and postmonsoon seasons. This suggests that farmers in subarea 3 did not plant extensively in April-May even though rainfall and soil water were as abundant as when the farmers in the other subareas planted rice. In other words, this result suggests that little motivation existed in subarea 3 to plant earlier in April-May, even though the farmers had enough soil water to plant in these months. This in turn suggests the motivation in the other subareas to plant earlier when possible. Considering the smaller amounts of rainfall at the end of the rainy season and postmonsoon season (September-October) in the other subareas compared with those in subarea 3 , the limited water availability at the end of the rice-growing season might be one of the motivations to plant earlier when possible, except in subarea 3 . The characteristic dominant rainfall on the western side of Tonle Sap Lake during the postmonsoon season was indicated by the earlier studies of Tsujimoto et al. (2018) and Tsujimoto and Koike (2013); this rainfall may be one of the reasons for later planting in subarea 3 around Battambang. On the other hand, the northeastern side of the lake (subarea 1, near Siem Reap) experiences smaller rainfall amounts through the end of the rainy season and into the postmonsoon season (September-October), which may be one of the reasons planting is enhanced in the earlier months in this subarea in years with above-average rainfall. The results indicating earlier planting against the accumulated rainfall amount in subareas 1 and 2 (Fig. 6a) can be attributed to such a motivation. However, the existence of other reasons, especially in terms of agronomic management, as well as rice cultivars, should be considered and be further studied in the future.

\section{Accuracy of satellite observations for rainfall and soil moisture}

The results regarding the dependency of the planting date on rainfall and soil moisture showed a clear difference in July, as described earlier in the manuscript. Although soil moisture is, in a general sense, considered more appropriate for use as an index to describe crop water availability than rainfall, both the spatial and temporal resolutions of the GSMaP rainfall data are higher than those of the AMSR-E/AMSR2 soil moisture data used in this study, and biases exist in both satellite estimations. Further validation and quantification of the accuracy of the
Table 1 Summary of the direction and significance of the correlations between the planting date and rainfall and between the planting date and soil moisture (Fig. 6b-e)

\begin{tabular}{|c|c|c|c|c|c|c|c|c|c|c|}
\hline \multirow[t]{2}{*}{ Subarea } & \multicolumn{5}{|c|}{ Rainfall } & \multicolumn{5}{|c|}{ Soil moisture } \\
\hline & Apr & May & Jun & Jul & Aug & Apr & May & Jun & Jul & Aug \\
\hline 1 & ++ & +++ & & --- & & ++ & +++ & & & -- \\
\hline 2 & +++ & +++ & + & - & +++ & ++ & ++ & -- & & \\
\hline 3 & & +++ & +++ & --- & & --- & -- & +++ & +++ & \\
\hline 4 & +++ & & - & -- & + & +++ & +++ & & +++ & + \\
\hline 5 & ++ & +++ & - & --- & ++ & +++ & +++ & --- & +++ & \\
\hline
\end{tabular}

Classification by the Pearson product-moment correlation coefficient $(r) .+++$ : $r>0.3 ;++$ : $0.3>r>0.2 ;+: 0.2>r>0.1 ;---: r<-0.3 ;--:-0.3<r<-0.2 ;-:-0.2<r<-0.1$. blank cell: weak correlation with $|r|<0.1$ 

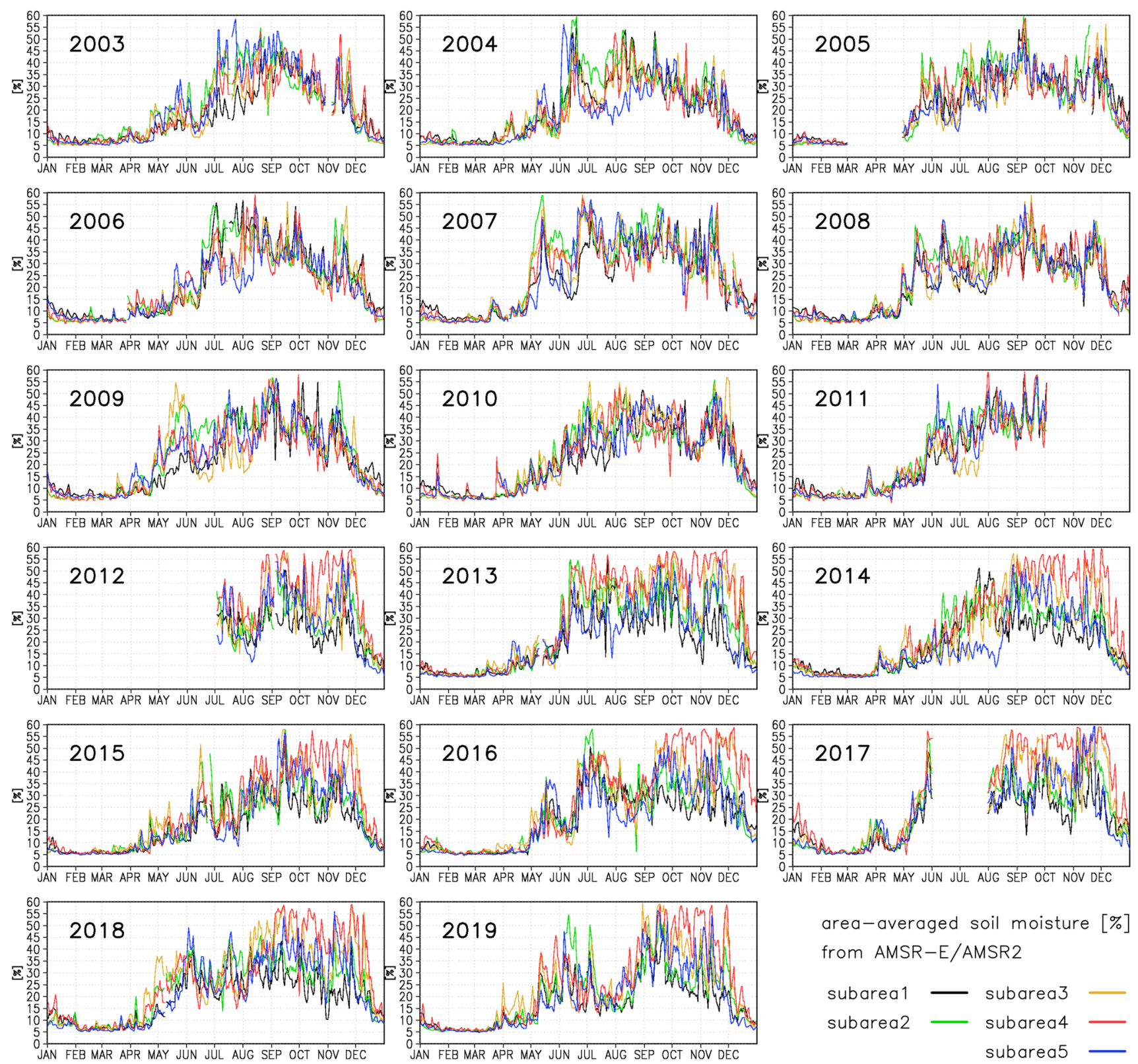

Fig. 7 Daily soil moisture from January 1 to December 31 for each year from 2003 to 2019. The area-averaged values for the five subareas are shown in lines of different colors

GSMaP rainfall and the AMSR-E/AMSR2 soil moisture over this region are necessary. In addition, land surface processes such as infiltration, surface runoff, soil water movement, and evapotranspiration, as well as soil properties, control soil moisture for a given rainfall amount; thus, further examinations on the quantification of soil moisture under a given rainfall amount are important to deepen this kind of study. Although further validation is needed, the AMSR-E/AMSR2 soil moisture products were suggested to provide good reference data for this kind of study, and these products are especially useful when high-spatiotemporal-resolution field observations on soil moisture are difficult to obtain.

\section{Dry spell occurrence}

Figure 7 shows the area-averaged daily soil moisture measurements from January 1 to December 31 for each year in each subarea. The soil moisture increased beginning in approximately May and was mostly higher than $20 \%$ after June. We suggest, therefore, that soil moisture was mostly maintained at a sufficiently high level after the maturation 


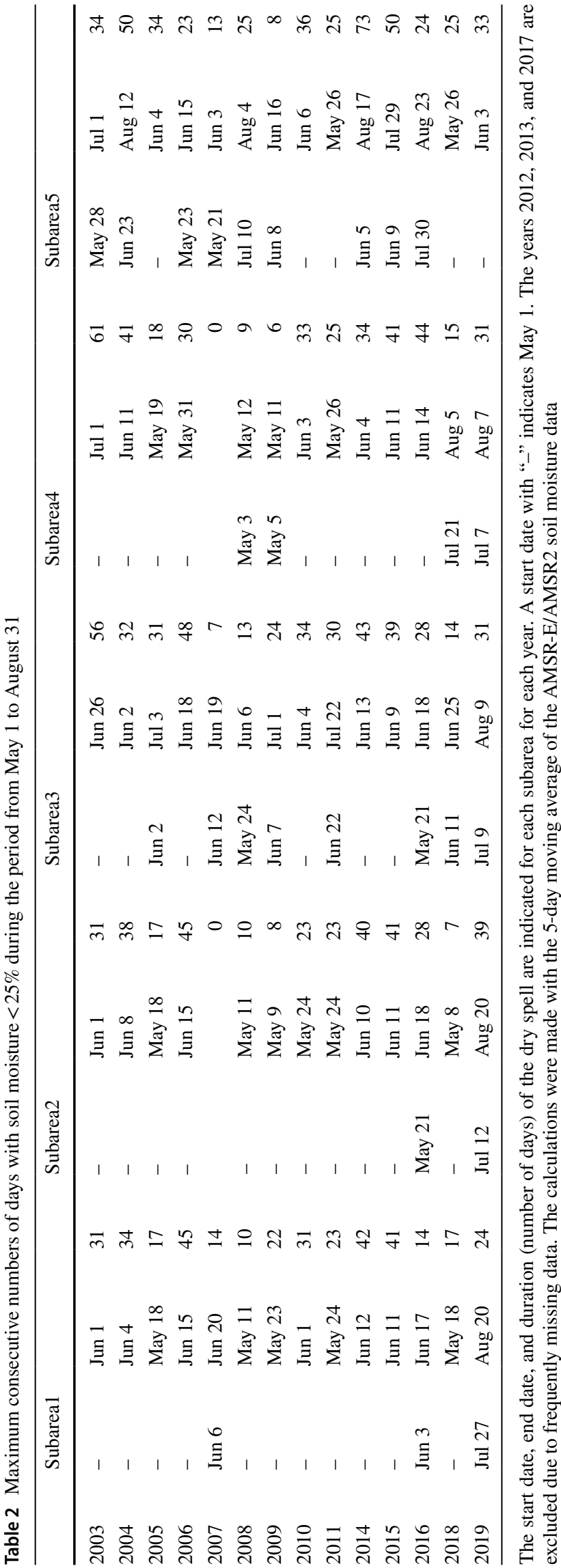

of the rainy season in June and in the later months, and soil moisture was not the limiting factor for planting in these months. On the other hand, a clearer relationship between the planting area and soil moisture was recognized in the earlier season, in April and May, except in subarea 3 on the western side of Tonle Sap Lake around Battambang and Pursat. Since the soil moisture is still increasing in April and May with the onset of the rainy season, soil wetness during April-May is thus considered to have a more significant effect on farmers' planting decisions in these months, and farmers often shifted planting to earlier dates if the soil was sufficiently wet. However, earlier planting in April and May (corresponding to the earlier onset of the rainy season) might be risky under changing climatic conditions in terms of avoiding dry spells after the onset of the rainy season.

Soil moisture generally starts increasing in May and remains high until October or November, but the seasonal evolution of soil moisture experiences large annual variations. The dry spell in 2019 was especially apparent and was more severe than that seen in normal years, as indicated by the decreased soil moisture recorded in July-August after it had increased beginning in May. To examine the extent of such dry spells, we counted the consecutive numbers of days with soil moisture values lower than $25 \%$ in each subarea in each year. The maximum numbers of dry days during the period from May 1 to August 31 is summarized in Table 2. For this calculation, we applied a 5-day moving average to the original AMSR-E and AMSR2 data to account for frequently missing data. If soil moisture gradually increased beginning in May and remained high after increasing, a dry spell did not appear, and thus, the maximum consecutive number of dry days started from May 1. In this case, we indicated "-_ for the start date in Table 2. In contrast, if a dry spell existed (i.e., if soil moisture was higher than $25 \%$ on May 1 but decreased and remained lower than $25 \%$ in the later period; this tendency was most apparent in 2019 (Fig. 7)), the start date was defined as another date in the year. If soil moisture remained higher than $25 \%$ across the target period, no dates were indicated as start or end dates, and the duration is shown as 0 in Table 2. Table 2 indicates the occasional appearance of dry spells, which occurred most frequently in 2015-2019 around the Tonle Sap Lake area (in subareas 1-4). Subarea 5, covering the region south of Phnom Penh, showed different characteristics compared to the other subareas around the lake, with more severe dry spells occurring in 2004, 2014, and 2015 and shorter spells in 2016-2019.

\section{Conclusions}

In this study, we examined the dependency of the planting date on rainfall and soil moisture in paddy fields in Cambodia to quantify farmers' empirical knowledge regarding their 
decision of the planting date, especially in rain-fed paddies. For the analysis, the globally accessible MODIS-EVI, the GSMaP rainfall products, and the AMSR-E/AMSR2 soil moisture products were used. Multiyear data from 2003 to 2019 were analyzed using remote sensing data from multiple satellites. From the EVI time series obtained by MODIS, the planting date was estimated at a 500-m spatial resolution for each studied year. The planting dates in rain-fed paddies ranged widely from April to September, and the planting date was most frequently recorded from June to August, during the full-monsoon season. The 2003-2019-averaged data indicated that planting occurred earlier on the northeastern side of Tonle Sap Lake (subarea 1, around the Siem Reap) on June 26 and later on the western side of the lake (subarea 3, south of Battambang) on July 19. Large annual fluctuations in the planting date were recognized in all five subareas, with the smallest fluctuations observed in subarea 3 .

Further analyses suggested that in years when planting was suppressed in the premonsoon season in April and May, it was greatly enhanced, compared with normal years, from June to August, and vice versa. The planting areas in April and May were found to have positive correlations with rainfall and soil moisture, suggesting that wetter-than-average conditions prompted farmers to plant larger areas in that season. In contrast, the relationship between the planting area and soil water availability was not obvious, or was even slightly negative, in the following full-monsoonseason months from June to August. Although an earlier study (Sawano et al. 2008) suggested the dependency of the planting area on the rainfall amount beginning in June in an adjacent region in northeast Thailand, the relationship in Cambodia determined in this study suggested significant annual variabilities in the planting area and rainfall amount in July, and clear relationships were not recognized in every studied year. Although enhanced plantings were recognized in wetter years in the premonsoon season (April and May) in subareas 1, 2, 4, and 5, this was not the case in subarea 3 , although subarea 3 had larger rainfall amounts than other subareas. Considering that the rainfall amount in subarea 3 was also larger in the postmonsoon season, the rainfall amount at the end of the rainy season and postmonsoon season also affected farmers' behavior in determining the planting date to avoid water shortages at the end of the ricegrowing season.

Analyses of the AMSR-E/AMSR2 data suggested that more frequent dry spells occurred after the onset of the rainy season in 2015-2019 compared to those recorded in the past period, in 2003-2014. Further studies of the potential changes in the frequency, timing, duration, and significance of dry spells under climate change conditions will be important.

This study suggests the applicability of AMSR2 data for this kind of study; this application is reasonable, considering that the annual variations in seasonal soil moisture that occur during the premonsoon and monsoon seasons are brought about by large-scale atmospheric conditions rather than by the spatial resolutions of their data sets. However, since this study relied on remote sensing data, further examination with field surveys is required for a detailed study. Nevertheless, our results can be a reference for developing further research to clarify farmers' empirical actions regarding their decision of the planting date.

Acknowledgements Parts of this research were supported by the Japan Society for the Promotion of Science (JSPS) KAKENHI Grant Numbers JP16K06503 and JP19KK0171 and also by the Earth Observation collaborative research (PI Number ER2GWF101) and Precipitation Measuring Mission (PMM 7th Research Announcement) projects by JAXA. The field survey was conducted with the assistance of Nana Kuriya and Risa Yamamoto. We are grateful to the Editors Profs. Masayuki Fujihara and Toshiaki Iida and two anonymous reviewers for their helpful and constructive comments that greatly contributed to improve the manuscript from the earlier version.

\section{Declarations}

Conflict of interest The authors declare that they have no conflict of interest.

Open Access This article is licensed under a Creative Commons Attribution 4.0 International License, which permits use, sharing, adaptation, distribution and reproduction in any medium or format, as long as you give appropriate credit to the original author(s) and the source, provide a link to the Creative Commons licence, and indicate if changes were made. The images or other third party material in this article are included in the article's Creative Commons licence, unless indicated otherwise in a credit line to the material. If material is not included in the article's Creative Commons licence and your intended use is not permitted by statutory regulation or exceeds the permitted use, you will need to obtain permission directly from the copyright holder. To view a copy of this licence, visit http://creativecommons.org/licenses/by/4.0/.

\section{References}

Babel MS, Agarwal A, Swain DK, Herath S (2011) Evaluation of climate change impacts and adaptation measures for rice cultivation in Northeast Thailand. Clim Res 46(2):137-146. https://doi.org/ $10.3354 / \mathrm{cr} 00978$

Bhuvaneswari K, Geethalakshmi V, Lakshmanan A, Anbhazhagan R, Sekhar DNU (2014) Climate change impact assessment and developing adaptation strategies for rice crop in western zone of Tamil Nadu. J Agrometeorol 16(1):38-43

CARDI (2013) Annual report 2012

CARDI (2014) Annual report 2013

Darzi-Naftchali A, Karandish F (2019) Adapting rice production to climate change for sustainable blue water consumption: an economic and virtual water analysis. Theor Appl Climatol 135:1-12. https:// doi.org/10.1007/s00704-017-2355-7

FAO (2019) FAOSTAT. http://www.fao.org/faostat/en/\#home. Accessed 10 March 2020

Hirooka Y, Homma K, Kodo T, Shiraiwa T, Soben K, Chann M, Tsujimoto K, Tamagawa K, Koike T (2016) Evaluation of cultivation 
environment and management based on LAI measurement in farmers' paddy fields in Pursat province, Cambodia. Field Crop Res 199:150-155. https://doi.org/10.1016/j.fcr.2016.08.031

Japan International Cooperation Agency (JICA) (2019) Irrigation development in Cambodia, status as of March 2019

JAXA (2016) Data users' manual for the advanced microwave scanning radiometer 2 (AMSR2) onboard the global change observation mission 1st - water "Shizuku" (GCOM-W1)

JAXA (2019) JAXA global rainfall watch. https://sharaku.eorc.jaxa.jp/ GSMaP/guide.html. Accessed 3 March 2020

JAXA (2020a) About AMSR2. https://suzaku.eorc.jaxa.jp/GCOM_W/ w_amsr2/whats_amsr2.html. Accessed 3 March 2020

JAXA (2020b) Globe portal system (G-Portal). https://gportal.jaxa.jp/ gpr/?lang=en. Accessed 3 March 2020

Kaihotsu I, Asanuma J, Aida K, Oyunbaatar D (2019) Evaluation of the AMSR2 L2 soil moisture product of JAXA on the Mongolian plateau over 7 years (2012-2018). SN Appl Sci 1:1477. https:// doi.org/10.1007/s42452-019-1488-y

Kea S, Li H, Shahriar S, Abdullahi NM, Phoak S, Touch T (2019) Factors influencing cambodian rice exports: an application of the dynamic panel gravity model. Emerg Mark Financ Trade 55(1):122. https://doi.org/10.1080/1540496X.2019.1673724

Krishnan P, Swain D, Bhaskar BC, Nayak S, Dash R (2007) Impact of elevated $\mathrm{CO}_{2}$ and temperature on rice yield and methods of adaptation as evaluated by crop simulation studies. Agric Ecosyst Environ 122(2):233-242. https://doi.org/10.1016/j.agee.2007.01. 019

Kubota T, Shige S, Hashizume H, Aonashi K, Takahashi N, Seto S, Takayabu YN, Ushio T, Nakagawa K, Iwanami K (2007) Global precipitation map using satellite-borne microwave radiometers by the GSMaP project: Production and validation. IEEE Trans Geosci Remote Sens 45(7):2259-2275. https://doi.org/10.1109/ TGRS.2007.895337

Kubota T, Ushio T, Shige S, Kida S, Kachi M, Okamoto K (2009) Verification of high-resolution satellite-based rainfall estimates around japan using a gauge-calibrated ground-radar dataset. J Meteorol Soc Jpn 87A:203-222. https://doi.org/10.2151/jmsj.87A.203

Li T, Angeles O, Radanielson A, Marcaida M, Manalo E (2015) Drought stress impacts of climate change on rainfed rice in South Asia. Clim Change 133(4):709-720. https://doi.org/10.1007/ s10584-015-1487-y

Li S, Wang Q, Chun J (2017) Impact assessment of climate change on rice productivity in the Indochinese Peninsula using a regionalscale crop model. Int J Climatol 37:1147-1160. https://doi.org/ 10.1002/joc. 5072

Loveland TR, Reed BC, Brown JF, Ohlen DO, Zhu Z, Yang L, Merchant JW (2000) Development of a global land cover characteristics database and IGBP discover from $1 \mathrm{~km}$ AVHRR data. Int $\mathbf{J}$ Remote Sens 21(6-7):1303-1330. https://doi.org/10.1080/01431 1600210191

Marteau R, Sultan B, Moron V, Alhassane A, Baron C, Traoré SB (2011) The onset of the rainy season and farmers' sowing strategy for pearl millet cultivation in southwest Niger. Agric Meteorol 151(10):1356-1369. https://doi.org/10.1016/j.agrformet.2011. 05.018

MOWRAM (2012) Climate change strategic plan for water resources and meteorology (2013-2017)

Nguyen DB, Clauss K, Cao S, Naeimi V, Kuenzer C, Wagner W (2015) Mapping rice seasonality in the Mekong Delta with multi-year Envisat ASAR WSM data. Remote Sens 7(12):15868-15893. https://doi.org/10.3390/rs71215808

Rahman MA, Kang S, Nagabhatla N, Macnee R (2017) Impacts of temperature and rainfall variation on rice productivity in major ecosystems of Bangladesh. Agric Food Secur 6:10. https://doi.org/ 10.1186/s40066-017-0089-5

Sawano S, Hasegawa T, Goto S, Konghakote P, Polthanee A, Ishigooka Y, Kuwagata T, Toritani H (2008) Modeling the dependence of the crop calendar for rain-fed rice on precipitation in Northeast Thailand. Paddy Water Environ 6:83-90. https://doi.org/10.1007/ s10333-007-0102-x

Shrestha S, Deb P, Bui TTT (2016) Adaptation strategies for rice cultivation under climate change in central Vietnam. Mitig Adapt Strat Glob Change 21:15-37. https://doi.org/10.1007/ s11027-014-9567-2

So IM, Tsujimoto K, Aida K, Tamagawa K, Ohta T, Koike T, Nukui T, Sobue S, Homma K (2014) Water and food security under climate change in Cambodia. Trans Jpn Soc Aeronaut Space Sci, Aerosp Technol Jpn 12(ists29):Tn_31-Tn_39. https://doi.org/10. 2322/tastj.12.Tn_31

Tsujimoto K, Masumoto T, Mitsuno T (2008) Seasonal changes in radiation and evaporation implied from the diurnal distribution of rainfall in the Lower Mekong. Hydrol Process 22(9):1257-1266. https://doi.org/10.1002/hyp.6935

Tsujimoto K, Koike T (2013) Land-lake breezes at low latitudes: the case of Tonle Sap Lake in Cambodia. J Geophys Res: Atmos 118(13):6970-6980. https://doi.org/10.1002/jgrd.50547

Tsujimoto K, Ohta T, Aida K, Tamakawa K, So Im M (2018) Diurnal pattern of rainfall in Cambodia: Its regional characteristics and local circulation. Prog Earth Planet Sci 5:39. https://doi.org/10. 1186/s40645-018-0192-7

Tsujimoto K, Ohta T, Hirooka Y, Homma K (2019) Estimation of planting date in paddy fields by time-series MODIS data for basinscale rice production modeling. Paddy Water Environ 17:83-90. https://doi.org/10.1007/s10333-019-00700-x

USGS (1996) Global 30 arc-second elevation (GTOPO30). https://doi. org/10.5066/F7DF6PQS

USGS (2018) Global land cover characterization (GLCC) version 1.2

USGS (2020a) MODIS/Aqua vegetation indices 16-day L3 global 250 m SIN grid. https://lpdaac.usgs.gov/products/myd13q1v006/. Accessed 28 February 2020

USGS (2020b) MODIS/Terra vegetation indices 16-day L3 global 250 m SIN grid. https://lpdaac.usgs.gov/products/mod13q1v006/. Accessed 28 February 2020

Wang Q, Chun JA, Lee WS, Li S, Seng V (2017) Shifting planting dates and fertilizer application rates as climate change adaptation strategies for two rice cultivars in Cambodia. J Clim Change Res 8(3):187-199. https://doi.org/10.15531/KSCCR.2017.8.3.187

Waongo M, Laux P, Kunstmann H (2015) Adaptation to climate change: the impacts of optimized planting dates on attainable maize yields under rainfed conditions in Burkina Faso. Agric Meteorol 205:23-39. https://doi.org/10.1016/j.agrformet.2015. 02.006

Wolf J, Ouattara K, Supit I (2015) Sowing rules for estimating rainfed yield potential of sorghum and maize in Burkina Faso. Agric Meteorol 214-215:208-218. https://doi.org/10.1016/j.agrformet. 2015.08.262

World Bank Group (2020) Climate change knowledge portal for development practitioners and policy makers, country Cambodia. https://climateknowledgeportal.worldbank.org/country/cambo dia. Accessed 10 March 2020

Yoon PR, Choi J-Y (2019) Effects of shift in growing season due to climate change on rice yield and crop water requirements. Paddy Water Environ 18:291-307. https://doi.org/10.1007/ s10333-019-00782-7 